\title{
Mobile technology use in a multidisciplinary healthcare team - factors and challenges
}

\author{
Pamela Spink \\ Faculty of Information Technology,Monash University \\ Pamela.Spink@monash.edu
}

\author{
Frada Burstein \\ Faculty of Information Technology, Monash University \\ Frada.Burstein@monash.edu
}

\begin{abstract}
Mobile technologies are being increasingly used in the health care sector to deliver quality care to patients through improved communication. While considerable research has been carried out in this area, there is limited research as to how mobile technology is being used by a multidisciplinary health care team (MHCT). This study aims to shed some light on the use of mobile technology by a MHCT. Using Activity Theory as a lens, we report on a qualitative study carried out in a large Australian hospital. This research identified the type of tasks and characteristics of the roles of the MHCT as important factors in understanding how they use mobile technology. The type of use for the technology was classified into spontaneous, restricted and potential use. Communication was found to be the key "spontaneous" use by the MHCT. The major challenges faced by the MHCT were privacy and security, and confidentiality.
\end{abstract}

\section{Introduction}

Traditional health care information systems have limitations and developments in the area of mobile technologies have led to a renewed interest in the adoption of mobile technology-based IT systems in the healthcare sector. Doctors, nurses, and allied health professionals are using mobile technologies to deliver quality care to patients through improved communication. This study focuses on the use of mobile technology in a multidisciplinary health care team (MHCT). A multidisciplinary team as defined by The Department of Health[1] and Mental Health Commission [2] comprises of a range of healthcare professionals from fields including allied professionals from a range of disciplines such as psychologists, speech and language therapists, occupational therapists, psychiatrists, specialist nurses, physiotherapists, nutritionists to mention a few $[1,2]$. Timely information access is highly critical in an increasingly complex and fast-paced healthcare environment and complexity of communication can hinder the quality of the service delivered. Poor information exchange between the clinicians could be a major source of errors and patient injury [3] thereby compromising patient safety. In time-critical medical situations, managing communications is crucial among the team to ensure awareness, coverage, response, and continual improvement. MHCTs in hospitals have shown to enhance communication, improved patient satisfaction and decreased the length of stay thereby improving health outcomes [4]. Mobile devices can be used for such emergencies to deliver information across cross-functional team members to confirm availability and escalate messages to the others as needed. As the access to patient information over the internet is increasingly becoming common in healthcare institutions, replacing traditional hospital discharge instructions using mobile technology has proved beneficial in terms of retention of information, adherence to self-care instructions and thereby increasing quality outcomes for the patients [5]. Research into mobile technology use in the healthcare setting (hospital), however, is fragmented. Contributions to this research area largely focus on the benefits of a particular mobile device; adoption/acceptance and attitudes/intentions of use by a particular health care provider as well as the barriers to adoption of this technology. Prior research conducted to evaluate the use of smartphones by $\mathrm{Wu}$ et al. [6] revealed that smartphones were perceived by the nurses as increasing efficiency and communication. The findings of this study were further backed up by Lo et al. [7] who have examined perceptions of General Internal Medicine (GIM) staff on the usage of Smartphone devices and a web paging system at two teaching hospitals in North America. While the study has no doubt contributed to literature towards 
mobile technology use in the multidisciplinary care team, the proposed research considers how mobile technologies (not limited to smartphones and Web paging) can support the multidisciplinary health care team in different contexts within the same hospital. Before any adoption of technology in an organization, it is important to explore and understand how the technology might support the MHCT team by identifying the factors of use, how they use the technology and the challenges that come with using the technology.

There is limited research undertaken to understand how a wide range of mobile technology is being used in a MHCT. Looking at such a wide range in this study we include PDAs, mobile phones/smartphones and tablet PCs. The care for a patient come together through the focus of many clinical disciplines - medicine, nursing, pharmacy, etc. and tasks in healthcare are highly interdependent and necessitate actions to be taken at particular locations, times, and by and for specific individuals. Hence, understanding the nature of the task, the role of the healthcare professionals and the type of mobile device used, in a team, is highly important in determining how mobile technology can support the MHCT.

Activity Theory [8] is a framework that helps to understand the relationship of humans and tools, with other influences within a social setting. In this study Activity Theory has been used as a lens and analytical tool to address the research question, "How does mobile technology support a multidisciplinary team in a hospital setting?" in the Australian context.

The paper commences with a review of the literature on the use of different types of mobile technologies by healthcare professionals. Next, the case study methodology is described followed by a discussion of findings and concludes with limitations and future direction of the research project.

\section{Literature Review - Use of mobile technology by healthcare professionals}

In this section, we highlight the importance of communication in a health care team, by providing research in the area of different mobile devices used by individual health care professionals.

\subsection{Use of PDAs by healthcare providers}

Mobile devices have plenty of functionalities and are capable of accessing and sharing information, anytime, anyplace [9]. Handheld computers combine the benefits of electronic patient records and paper charts and are relatively inexpensive [10] and these devices are being increasingly used by physicians for scheduling, accessing drug references and patient data [11]. Improved technology, with larger memory capacity, higher screen resolution, faster processors, and wireless connectivity has broadened the potential roles for mobile devices in critical care. Several features of PDAs like personal information management, decision support through educational materials and remote access to radiology systems make workflow more efficient [12] and a useful tool for viewing radiological images.

\subsection{Use of mobile phones/smartphones by healthcare providers}

Smartphones are becoming popular due to their affordability, immediate access to information, connectivity and mobility. Healthcare professionals are embracing smartphones for delivery of patient care and help change behavior, better health outcomes and lower healthcare costs. Smartphones can connect to the internet, send messages, record video, and use applications or "apps". They can be used to transmit high-quality photographs safely and effectively in clinical practice [13]. The apps make smartphones useful tools at the point of care and clinical communication [14], health monitoring and decision support [15]. Mental health professionals are using smartphones for research and their daily work to conduct interviews and structured therapy [16]. Results from a research survey conducted by Nerminathan et. al [17] examining mobile device usage by doctors in a clinical setting, has revealed that $91 \%$ owned a smartphone and $88 \%$ of the doctors used their mobile devices to enhance efficiency in their work setting.

\subsection{Use of tablet PCs by healthcare providers}

A survey by Manhattan Research [18] conducted in 2012 on 3,015 physicians in 25 specialties concluded that the adoption of tablet computers by physicians has grown rapidly. Half of the $62 \%$ of physicians who owned a tablet, used them at the point of care. $39 \%$ of the physicians used SMS, instant messaging and online video conferencing to communicate with their patients.[18].

Providing safe, effective and patient-centered care necessitates efficient and effective communication. Being able to access comprehensive patient information when it is needed enables the nurses to carry out the physician's orders much more safely and accurately as it enables the nurses to 
identify patients' needs, monitor their condition and prevent complications. In hospitals, however, nurses are faced with challenges of using a paper-based delivery system namely shift communication among nurses and access to patient information. The use of an integrated system of pocket PCs and PC with the hospital mainframe system has been positive in improving the efficiency of communication in shift reports and access to patient information and nurses found pocket PCs to be very useful [19].

Horng, Goss, Chen, and Nathanson conducted a mixed-method study among physicians in a tertiary academic teaching hospital in Massachusetts to evaluate the usage of tablets by physicians in an emergency department [20]. The usage of computer workstations at the emergency department and the use of tablets at beside was compared. Results indicated that the time spent on the computer workstations decreased when physicians use the tablet to deliver patient care. While this study has supported positively towards physicians' use of tablet computers, as the authors suggest, further study is required into how tablets can impact a physician's workflow, productivity, patient satisfaction and quality and safety of care. Tablet computers also have the potential as a remote radiological image review and teleconsultation device, considering its technological improvements over PDAs [21].

\section{Theoretical Framework}

Activity Theory according to Engestrom, helps understand dialogues, multiple perspectives, and interaction of activity systems [8]. It captures all aspects of the activity system to better understand the nature of the activities. Activity Theory is characterized by principles such as hierarchical structure, object orientedness, internalization/externalization, tool mediation and development [22]. The basic unit of analysis in Activity Theory is human activity and is described through related elements where the activity is broken into (1) Object of the activity (or objective, i.e., the goals and intentions), (2) Subjects in the activity (i.e., the people engaged in it), (3) Tools mediating the activity (anything physical, e.g., computers; or mental, e.g., models), (4) Rules and regulations (norms that circumscribe the activity), (5) Division of labour (e.g., actions undertaken by individuals within the group versus tasks that are a group responsibility, (6) Community (individuals directly or indirectly involved in the tasks) and (7) Outcome (i.e., the results and final products of the defined objectives). Activity Theory has been used in healthcare to determine systemic contradictions that affect doctor-patient interaction [23], information management practices in maternity care network [24] and in understanding mobile technologymediated work in policing [25].

Activity Theory (AT) has been chosen for this study, as this framework is highly appropriate for qualitative research that explores how organizations understand and meet the challenges, by analyzing and providing deep and rich understandings of complex dynamic settings such as healthcare context. Activities are composed of goal-directed actions that must be undertaken to fulfill the object. Different actions may be undertaken by different subjects to meet the same object. At a collective level, Activity Theory provides a lens for understanding and coordinating the complex task of taking account of activity at a systemic level. Activity Theory supports tools and the tools do have an influence over the interaction between the subject and the object [26] bringing about change. Change, besides bringing improvements brings with it challenges and complications that need to address by the participants in obtaining the objectives. Though tools have limitations, they do have the potential to manipulate and transform objects [27]. This study intends to explore deeper into the MHCT and their interaction with mobile technology and understand the challenges that they face in using the technology.

\section{The Methodology}

The case study organization chosen for this research is a large Australian public hospital providing specialist leading-edge services as well as tertiary teaching. Four multidisciplinary teams, from major units of the hospital - Radiation Oncology, Colorectal Surgery, Gastro Unit, and the Intensive Care Unit participated in the research. A multidisciplinary team (in this research) comprises at least one physician, one nurse and one allied professional.

\subsection{Research approach \& Data Collection}

A multiple-case, interpretive design was employed as this approach is more appropriate and suited for extension of theory and cross-case analysis [28]. Even though there is no hard and fast rule about the sample size in this design, Yin suggests six to ten cases [29] while Creswell [30] believes that 4-5 cases should be enough. There are no concrete guidelines either for attaining data saturation [31]. However, the sample size can be determined by the number of cases required to reach 
saturation, that is, data collection until no significant new findings are revealed [29]. Data collection was conducted through face-to-face interviews as the primary source and document analysis. The interviews lasted approximately 30-40 minutes. Interviews were semi-structured, and questions were formulated based on the theoretical concepts from Activity Theory. Participants were chosen employing purposive sampling, wherein the selection involved a small number of data sources to meet the required criteria, followed by a snowball sample. This technique was more suitable as the research required teams comprising of at least one physician, one nurse and one allied professional working in the same team.

Ethics approval for collecting data for this research work was sought from the Ethics Committee of the researchers' institution. On approval, an explanatory statement requesting participation was emailed to the chosen participants of the case study organization. Table 1 summarizes the details of each multidisciplinary health care team (MHCT).

Table 1. Case summaries of the Multidisciplinary healthcare teams

\begin{tabular}{|l|l|l|l|}
\hline \multicolumn{4}{|l|}{ A. RADIATION ONCOLOGY - CASE 1 } \\
\hline Participant & Role & Gender & Exp. (yrs) \\
\hline A1P & Physician & Male & 30 \\
\hline A2P & Physician & Male & 15 \\
\hline A3N & Nurse & Female & 35 \\
\hline A4AP & Radiation T & Male & 15 \\
\hline A5AP & Radiation T & Male & $15+$ \\
\hline \multicolumn{5}{|l|}{} \\
\hline B. COLORECTAL SURGERY - CASE 2 \\
\hline Participant & Role & Gender & Exp. (yrs) \\
\hline B1P & Physician & Male & 30 \\
\hline B2P & Physician & Female & 15 \\
\hline B3P & Physician & Female & 35 \\
\hline B4N & Nurse & Female & 15 \\
\hline B5AP & Pathologist & Female & $15+$ \\
\hline \multicolumn{5}{|l|}{} \\
\hline C. GASTRO - CASE 3 \\
\hline Participant & Role & Gender & Exp. (yrs) \\
\hline C1P & Physician & Male & $15+$ \\
\hline C2N & Nurse & Female & 15 \\
\hline C3N & Nurse & Female & $30+$ \\
\hline C4AP & Pharmacist & Female & $5+$ \\
\hline \multicolumn{5}{|l|}{} \\
\hline D. INTENSIVE CARE - CASE 4 \\
\hline Participant & Role & Gender & Exp. (yrs) \\
\hline D1P & Physician & Male & $20+$ \\
\hline
\end{tabular}

\begin{tabular}{|l|l|l|l|}
\hline D2N & Nurse & Female & $5+$ \\
\hline D3N & Nurse & Male & 30 \\
\hline D4AP & Dietician & Female & $40+$ \\
\hline
\end{tabular}

\subsection{Data Analysis}

Data collected was analyzed using NVivo11 software and thematic analysis. The coding process began with several iterations of reading and immersing [32] in the transcribed data to get an idea of the emerging themes, followed by developing a coding structure, using the deductive approach suggested by Miles \& Huberman [33]. With the predefined themes as the basis, thematic analysis was employed to reduce data further. Themes were reviewed to ensure coherency and meaning within data in themes while maintaining distinctions between the themes [34]. Analyzing the data as they were being collected helped determine the saturation limit. After analyzing the four cases, the data did not reveal any new themes and hence four cases were deemed sufficient to answer the research question.

\subsection{The Activity System}

In the activity system of this study, the overall objective of the MHCT is to deliver quality care to patients. The subjects are the physicians, nurses and allied health professionals working together to accomplish this objective through interactions of "tools", in this study "mobile technology". The subjects in the activity though they have different roles and tasks, work as a team to achieve the same objective. Rules are the policies and guidelines that govern the tasks that the MHCT performs, while the division of labor refers to the roles and responsibilities of the MHCT team members. Community refers to the organizations/individuals who directly or indirectly interact with the MHCT. In order to answer the research question "How does mobile technology support the MHCT in a hospital setting?", the participants or the "subjects" of the MHCT were asked questions about their role and the type of tasks that they performed, followed by questions on how they use mobile technologies to assist them in their tasks (Table 2). Table 2 presents the empirical study instrument used in this study. 
Table 2. Empirical Study Instrument

\begin{tabular}{|c|c|c|}
\hline Concepts & Meaning & $\begin{array}{c}\text { Interview } \\
\text { Questions }\end{array}$ \\
\hline $\begin{array}{l}\text { Subject - } \\
\text { who are } \\
\text { involved in } \\
\text { the activity? }\end{array}$ & $\begin{array}{l}\text { The multidisciplinary } \\
\text { health care team - } \\
\text { Physicians, nurses and } \\
\text { allied professionals who } \\
\text { might use mobile } \\
\text { technology. }\end{array}$ & $\begin{array}{l}\text { Based on } \\
\text { experience, work, } \\
\text { role, and tasks; } \\
\text { Kinds of interaction } \\
\text { with other } \\
\text { healthcare } \\
\text { professionals }\end{array}$ \\
\hline $\begin{array}{l}\text { Object of } \\
\text { the activity }\end{array}$ & $\begin{array}{l}\text { The purpose of the } \\
\text { activity and what they } \\
\text { want to achieve - } \\
\text { improved health outcomes }\end{array}$ & $\begin{array}{l}\text { Based on the } \\
\text { usefulness of mobile } \\
\text { technologies in their } \\
\text { work }\end{array}$ \\
\hline $\begin{array}{l}\text { Tool used to } \\
\text { carry out the } \\
\text { activity }\end{array}$ & $\begin{array}{l}\text { The type of } \\
\text { mobile technology } \\
\text { Computer on wheels } \\
\text { (COWs), Personal Digital } \\
\text { Assistants (PDAs), } \\
\text { Laptops, } \\
\text { Smartphones and } \\
\text { tablet PCs that are } \\
\text { being used? }\end{array}$ & $\begin{array}{l}\text { Based on the type of } \\
\text { mobile technologies } \\
\text { that they might use } \\
\text { and the tasks they } \\
\text { might use them for } \\
\text { while working as a } \\
\text { team }\end{array}$ \\
\hline $\begin{array}{l}\text { Rules- Are } \\
\text { there rules and } \\
\text { regulations } \\
\text { governing the } \\
\text { activity? }\end{array}$ & $\begin{array}{l}\text { Policies and guidelines } \\
\text { governing tasks performed } \\
\text { by the multidisciplinary }\end{array}$ & $\begin{array}{l}\text { Based on the rules } \\
\text { that MHCT has to } \\
\text { follow. }\end{array}$ \\
\hline Outcome & $\begin{array}{l}\text { Outcome of the objective } \\
\text { of the activity } \\
\text { quality care. }\end{array}$ & $\begin{array}{l}\text { Determined } \\
\text { based on the } \\
\text { objective }\end{array}$ \\
\hline $\begin{array}{l}\text { Division of } \\
\text { labor - who is } \\
\text { responsible for } \\
\text { what? }\end{array}$ & $\begin{array}{l}\text { Individual and shared } \\
\text { tasks of the } \\
\text { Multidisciplinary health } \\
\text { care team }\end{array}$ & $\begin{array}{l}\text { Based on } \\
\text { individual tasks } \\
\text { and shared tasks } \\
\text { that the MHCT } \\
\text { perform }\end{array}$ \\
\hline $\begin{array}{l}\text { Communities- } \\
\text { individuals } \\
\text { directly or } \\
\text { indirectly } \\
\text { involved in the } \\
\text { tasks }\end{array}$ & $\begin{array}{l}\text { Multidisciplinary health } \\
\text { care team members' } \\
\text { involvement directly or } \\
\text { indirectly in the } \\
\text { community/organization } \\
\text { external to their } \\
\text { organization }\end{array}$ & $\begin{array}{l}\text { Based on their } \\
\text { interaction with } \\
\text { internal and } \\
\text { external } \\
\text { individuals/groups }\end{array}$ \\
\hline
\end{tabular}

\section{Discussion of findings}

\subsection{The type of tasks and role characteristic of the MHCT}

The type of tasks and role characteristics of the multidisciplinary teams have been identified as factors influencing the use of mobile technology. Findings from the cases reveal that tasks that the multidisciplinary teams perform, be it a physician, nurse or allied professional can be categorized as "Clinical tasks", those that relate directly to treatment and care, and "Non-clinical tasks" such as the administrative tasks. For example, in the Radiation Oncology (MHCT), the tasks that the
Physicians perform are clinical, as participants report,

"... my role was to really offer the patient radiotherapy ... before their surgery to treating rectal cancer to help shrink cancer and improve their local control and survival". (A1P).

"Tasks in theatre is operating, performing operations. In the out-patient clinics, it's seeing the patients who come to clinics as new patients and follow up patients. In the colonoscopes, it's doing the colonoscopies (B3P)

"Also, going to the theatre and doing operations...Colonoscopies...as well, as outpatient clinics." (B2P)

While the physicians initiate the procedure and have a major role to play in the multidisciplinary team delivering care to the patient, the procedure cannot be complete without the input from the nurse

"My role at this time is preparing them for this test that they have to have done. Might be that they have to have the urine flow test, have enema, have some medication to make them relaxed, then prepare the trolley that they use during the procedure and then afterward, its making arrangements with the patients to come back so we can do all of their work up ready for coming in to the hospital" ( $\mathbf{A 3 N})$

The role of allied professionals in the team comes into play once the patient is ready to undergo radiation therapy and they perform tasks such as planning the treatment, run experiments and quality assurance checks.

"So, we'll do a CT scan, that will define the area they want to treat within that CT scan. Then I would come up with the plan" (A5AP)

Non-clinical tasks performed by the multidisciplinary team as one participant reports "Mainly in the office doing paperwork, writing letters or thinking about research" (A1P) "So, I attend routinely probably four multidisciplinary meetings." (A2P)

"Education to patients, to families, to external providers through the phone here" (A3N) "Interdepartmental teaching for some of the interns and small sessions for nursing groups. But we also do a lecture to medical radiation students, guest lecturers" (A4AP)

Therefore, the tasks that the multidisciplinary teams undertake in delivering care to a patient fall into "Clinical" and "Non-Clinical" tasks which 
provide a better understanding of the tasks that the subject performs. However, since the subjects here are the multidisciplinary team, care for the patients is an integrated approach from the team members with varied skills, experience, and qualifications. Through the analysis, therefore, the theme that emerged which provides more contextual information about the subjects is "Subject Role Characteristics".

When participants were asked questions about their role in the multidisciplinary teams, various characteristics emerged such as what their role involved, their experience, the number of roles they undertook and their mobility according to the demands of their role for e.g., the physicians were moving within the unit as well as visiting external hospitals thereby characterized as "Highly Mobile"

"We work across different campuses. We work at A, at M, I would often start at 7 or 7.30 in the morning sometimes seeing consultations for patients to treat here at B. I'd probably drive down the road, come here at 8:00 o clock and I'll see a mixture of patients in the clinic..." (A2P)

Whereas the nurse fell into the "fairly mobile" category. Though the job of the nurse demands a certain amount of mobility, the role did not require visits to external hospitals and as one participant reports:

"Probably half of my day 4-5 hrs. spent doing those things, administrative works. I do not have to very often go to other hospitals. Mostly telephone contacts with people outside of here but also with our patients. Running in services within the hospital for nursing staff, in other departments then I have a few hours of meeting every week. A bit of walking. Plenty of time spent up and down the stairs but also walking to other areas around the hospital. And a lot of footwork.." (A3N)

While the Allied Professionals seem to be "less mobile" as their roles did not involve doing rounds in the hospital or even visiting other hospitals.

"And we don't really do rounds within the hospital and don't really visit other hospitals and occasionally I might go down to travel but it's only maybe once or twice a year, it's not very often at all. So, the majority of time within that office type of situation...." (A4AP)

The findings, therefore, suggest that mobile technologies are being used for both 'Clinical' and 'Non-clinical' tasks and the characteristics of their roles do influence the extent to which the multidisciplinary team uses these technologies. If healthcare professionals are highly mobile, where they travel between locations within and outside the hospital and have the responsibility of multiple roles, then they seem to have more use for the technologies. The physicians who took part in the study held multiple roles, which in turn necessitated more responsibilities. Being mobile was one of the characteristics of their role, therefore being accessible from anywhere, anytime is crucial for their team. The nurses on the other hand, though move around and within the wards, their roles did not require them to move to other locations frequently. The allied professionals seemed to be "less mobile" as their roles did not often require them to move to other locations in the hospital or outside the hospital. Therefore, the role of the multidisciplinary team is characterized by the nature of their work they perform, the level of mobility that their roles demand, level of responsibility, whether they held single or multiple roles, their experience and their interaction within their team. As in Activity Theory, the "subject" can be a group or individual performing different tasks in the activity system, however, working towards the same object. In achieving their object, there is communication and interaction taking place among the team members. In a clinical or hospital setting, physicians and other healthcare professionals have to work in multiple locations such as patient visits inwards, offices, clinics, operating theatres and laboratories where communication and collaboration with individuals $[35,36]$. Collaboration and co-operation are the key factors for the success of a team pursuing a common goal [37].

\subsection{Type of mobile technology use}

The type of mobile technology use fall into i) Spontaneous use ii) Restricted use and iii) Potential use. During the interactions that take place between the multidisciplinary team members, the need to use the technology in urgent matters like the nurse contacting the physician or physician contacting the allied professional or the nurse, the act is "spontaneous" whereas when a physician or a nurse wants to take a picture of the patient as in the case of a surgery to get the surgeon's opinion, for clinical purposes, the use is "restricted" and they have to think twice before using the mobile.

"For this particular patient, we've consent from the patient's relatives. We have been taking photos of her wound". (B2P) 
The MHCT is required to obtain the patient's consent, permitting them to take the picture as long as the pictures are deleted once the purpose is fulfilled. Besides using mobile technology spontaneously as well as in a restrictive manner, the MHCT see potential use for the technology for tasks that they would like to perform such as being able to access patient records or ordering blood test using mobile technology. Currently, they are unable able to perform these tasks using mobile technology.

"Yes. So when I was at xx hospital, I was able to order a test, order a blood test, order and review them on a specific system on my iPad which we're not able to do as far as I know through "(B1P)

"I would like to be able to order tests on my device. Because at the moment, every time you have to order something. You have to look it up on a computer". (D2P)

"I think I would like to be able to order imaging electronically in the private sector" (A2P)

\subsection{Communication as the key "spontaneous" use of mobile technology}

Findings suggest that MHCTs use mobile technology spontaneously for communication. In using mobile technologies as "tool", the participants were asked questions regarding its use in the team and as participants report:

"Transfer email, for example, it is easy. Of the mobile devices, I would say email. Other things would be I guess, increasingly SMS messages to other staff, so all management things. Phoning them or SMS them or emailing them" (A1P)

"Use it for communicating with the teams or communicating with my interns and my registrars. They give us updates on results during the day and update on the patient's progress or if there is a problem, they will contact us via my mobile. (B2P)

"I'm in theatre then they will either send me a message or they will call me on my phone to send me to go and see this patient, patient care will be the number one use". (B2P)

Communication has been identified as the primary use of mobile technology, in addition to being used as a device to access and contact other team members

"Keep track of doctors. So, if I need a doctor for anything, rather than having to go to a computer and log on to the paging system and send them a page, I will just send a text message or just call them directly and they will call me back. Usually, text message" (A3N)

Other notable uses of mobile technology identified are data management, immediate feedback, accessing information, patient monitoring and, contacting and tracking.

"Use mobile phones. Yeah, constantly phone calls and text messages and picture messages. Quite often if there is something an error message that you see, you take a snapshot of the screen and send it from your phone to their phone instantly and have all the details". (A4AP)

"To look things up, I have got some apps on the iPhone that I can use as references. So, for a meeting, for example, there is no paper, it is all PDFs on the iPad. Similarly, academic papers there are no paper copies". (A1P)

"Keep track of doctors. So if I need a doctor for anything, rather than having to go to a computer and $\log$ on to the paging system and send them a page, I will just send a text message or just call them directly and they will call me back" (A3N)

While the role of the multidisciplinary team seems to influence the extent to which they use mobile technologies, the primary use for the technology within the team is communication. Findings reveal that communication taking place through the use of mobile technologies can be more efficient and effective within a team and effective communication is crucial for successful collaboration [38] and use of mobile technologies, enhance communication, affect information sharing in the organisational system between interdisciplinary healthcare providers (physician, nurses and respiratory therapists) in the delivery of care [39]. Mobile technology can positively impact error prevention, access to information and management of data $[40,41]$ and this seems to align with the findings of this study that data management, immediate feedback and accessing information have been identified as other uses of mobile technology within the team.

\subsection{Challenges of mobile technology use}

Engstrom and Miettinen describe contradictions as "the motive force of change and development" (p. 9) [42]. Contradictions are tensions or inconsistencies in an activity system causing changes or imbalances in the activity or the people [43] however, they are necessary in an activity system for change and development. The MHCTs have faced few challenges in using mobile technology for their tasks. 
While the MHCT used mobile technology spontaneously for communication, they used the technology in a restricted manner for data management. A physician or a nurse has to obtain the patient's consent when using a smartphone to produce and store medical images. They need to be conscious of patient confidentiality, privacy, and security of the data captured, which needs to be deleted from the mobile device as there were little to no guidelines regarding the use of the device.

"... ensuring that we maintain confidentiality, we have to be quite conscious that we have to maintain the confidentiality of patient data."(B1P)

"I think confidentiality and ease of use. You want to make sure that things to do with health are maintained securely. So that the data that you're transmitting is being used responsibly" (D2P).

Even though the MHCTs are keen on using their mobile devices, the lack of clear mobile policies and in general mobile strategies pose a significant challenge. As there is no enterprise-wide deployment of mobile devices, the MHCT team members either use their personal devices or if eligible, purchase mobile devices through the electronic aid funding that is available to them.

“...I'm not exactly aware if the hospital does have a formal mobile device policy with regards to personal devices"(C1P)

"So doctors can get some funding giving them access to electronic aids. Now under the Victoria award committee, three or four years where you can access professional aids. Everyone buys mobile devices. It is not something that is supported by all services but we do it ourselves" (A2P)

Accessibility seems to be yet another challenge. The findings suggest that the MHCT often cannot use mobile technology as flexibly as they could. For example, if a physician wants to follow up on a patient's results that was approved by another doctor, the physician has to ring up and gain access to the results. This adds to both the complexity, timewasting, and loss of humanity in dealing with the patients.

"I can be sitting there and I cannot get the results and then I got to go all the way up and I have 15 min to see the patient and what I can I do?. Sometimes I have to get the results later and ring them up. We can harness technology but we are also very limited by a lot of other laws relating to accessing it" (A2P)

Findings also revealed that poor wireless connectivity was a significant challenge faced by one particular multidisciplinary team (Case 1) in using mobile technology. The radiation oncology unit is located underground because of its shielding requirements. Wireless networks are susceptible to obstructions such as thick walls and ceilings and thus weak signals prevent the MHCT in using their mobile devices effectively,

"The hospital has a wireless network but it does not reach our department well enough for us to be able to use mobile devices effectively. We need to set up our own wireless network, which is troublesome with the hospital because they will not let our wireless network to connect with theirs to share databases and things",

Figure 1 provides the outcome of this research, the activity system for mobile technology use in a MHCT. The subject task types and subject role characteristics as factors that influence the use of mobile technology. The type of mobile technology use and the key uses represented by task characteristics.

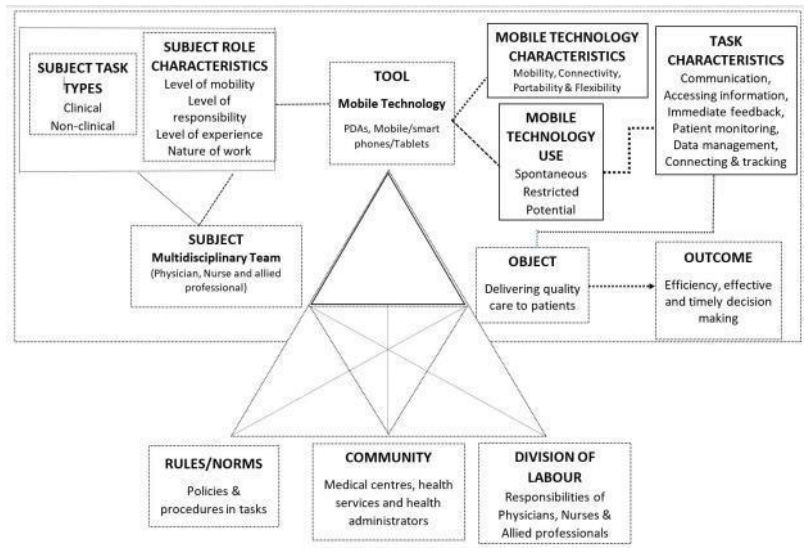

Figure 1. Mobile technology use
in a multidisciplinary team

\section{Contributions}

Modern healthcare is predominantly delivered by multidisciplinary health care teams. For the members of the team to be "on the same page" it is imperative to facilitate consistent, reliable, and up to date information exchange channels. With mobile technology being accessible and widely used by the majority of professionals and public - it was a plausible research proposition to look into the healthcare teams' use of mobile technology in their workplace. Thus, this study contributes to the literature by empirically illustrating how mobile technology was used in a multidisciplinary health 
care team in a public hospital in Australia. This setting has not been studied before and provides an interesting case for understanding the advantages and challenges in mobile technology use. Using Activity Theory, this study has proposed an extended and more specific framework, depicted in Figure 1, to explain the use of mobile technology in a MHCT. Based on the findings, this research sheds some insight and creates an awareness of mobile technology use by MHCT, thereby prompting the organizations to propose appropriate mobile device strategies and policies to realize the potential in using mobile technology in patient monitoring and clinical decision making. Understanding the importance of communication as the key spontaneous use of the technology, policymakers in the organization will be able to implement clear bring your own device (BYOD) policies thereby enhancing coordination of care by the MHCTs. For researchers, this study provides a foundation to further explore this area in other organizations.

\section{Conclusion}

The study set out to understand the use of mobile technology in a multidisciplinary healthcare team using Activity Theory as a lens and an analytical tool to get a deeper understanding into the "Subject" and how they might use mobile technology, for what tasks they use it and the challenges that they face in using the technology. Drawing on qualitative data from four cases, the research has revealed that the nature of tasks and role characteristics of the MHCTs as factors in understanding how the MCHTs use mobile technology. While communication has emerged as the key purpose of the use of technology and used spontaneously across cases, they use it in a "restricted manner" for data management and they find significant potential use for the technology. The other notable uses by the team are for immediate feedback and accessing information. While all the four cases reveal privacy \& confidentiality and accessibility as the main challenges, only one case revealed poor wireless connectivity as one of their main challenges in using the technology.

\section{Limitations and further research}

As this was a qualitative study to provide deeper insights into how a MHCT uses mobile technology in an Australian hospital setting, the findings are primarily based on data collected from face to face interviews, besides some documentation analysis. Non-participant observation was also planned but abandoned due to i) limitations of access to most of the MHCT members and ii) proved ineffective as it was difficult to determine exactly for what purpose the MHCT were using the mobile technology. Future data collection is planned to validate the results by conducting a follow-up survey on this topic with the participants.

\section{Acknowledgement}

This research was partly supported by Australian Research Council (ARC) funding, Discovery Program Project Number DP140100047.

\section{References}

[1] Department of Health, "Multidisciplinary Teams (MDTs)", activ2015, Retrieved from Northern Territory Government of Australia.

[2] Mental Health Commission, "Multidisciplinary Team Working: From Theory To Practice: Discussion Paper (1.84 MB)" Lenus.ie. N. p., 2006.

[3] Kohn, L. "To err is human: an interview with the Institute of Medicine's Linda Kohn", The Joint Commission journal on quality improvement, 2000, 26(4), pp. 227-234.

[4] Epstein, N.E., "Multidisciplinary in-hospital teams improve patient outcomes: A review", Surgical Neurology International, 2014, 5(Suppl 7), pp. S295-303.

[5] Holt, J E., Flint, E. P., Bowers, M. T., "Got the picture? Using mobile phone technology to reinforce discharge instructions". American Journal of Nursing, 2011, 111(8), pp. 47-51

[6] Wu, R.C., Morra, D, Quan, S, Lai, S, Zanjani, S, Abram, H, Rossos, P.G., "The use of smartphones for clinical communication on internal medicine wards", Journal of Hospital Medicine, 2010, 5(5), pp.553-559

[7] ] Lo V, Wu R.C., Morra D, Lee L, Reeves S, "The use of smartphones in general and internal medicine units: A boon or a bane to the promotion of interprofessional collaboration?", Journal of Interprofessional Care, 2012, 26(4), pp.276-282

[8] Engeström, Y., "Learning by expanding: An activitytheoretical approach to developmental research", Cambridge: Cambridge University Press, 1987.

[9] Bardram, J. E., "Temporal coordination -on time and coordination of collaborative activities at a surgical department", (CSCW), 9, 2000, pp.157-187.

[10] Ebell, M., \& Rovner, D., "Information in the Palm of your hand", Journal of Family Practice, 49.

[11] Lapinsky S.E., Weshler J, Mehta S, Varkul M, Hallett D, Stewart T, E., "Handheld computers in critical care", Critical Care, 2001, 5(4), pp.227-31.

[12] Flanders, A. E., Wiggins, R. H., and M.E. Gozum, "Handheld computers in radiology", Radiographics, 2003, 23(4), pp. 1035-1047.

[13] Joseph, B., V. Pandit, J. Wynne, H. A, A. Tang, N. Kulvatunyou, A. Webster, T. et al, "Telephotography in 
trauma: a 2-year clinical experience.", Telemedicine and eHealth, 2014, 20(4), pp.342-345.

[14] Mosa,ASM., Yoo,I.\& Sheets,L. "A Systematic Review of Healthcare Applications for Smartphones", BMC Medical Informatics \& Decision Making, 2012, $12 / 67$.

[15] Oscar, R., "Smarter healthcare: Mobile Technology Can Improve Pharmacy Utilization, Cut Costs", Benefits Magazine, 2013, 50(5), pp.22-26.

[16] Epstein, J., and W. A. Bequett, "Smart Phone Applications in Clinical Practice", Journal of Mental Health Counselling, 2013, 35(4), pp.283-295.

[17 ] Nerminathan, A, et al., "Doctors' use of mobile devices in the clinical setting: a mixed-methods study", International Medical Journal, 2017, 47(3), pp. 291-298.

[18] Pulse, U. S., Taking the Manhattan Research., 2012 SRC - GoogleScholar.

[19] Chang, K., Lutes, K., D, Braswell, M., L, \& Nielsen, J., K., "Nurses' perceptions of using a pocket PC for shift reports and patient care", International Journal of Healthcare Information Systems and Informatics, 2006, 52(12).

[20] Horng, S., Goss, F., Chen, R., \& Nathanson, L., "Prospective pilot study of a tablet computer in an Emergency Department", International Journal of Medical Information, 2012, 81(5), pp. 314-319.

[21] John, S., Poh, A. C. C., Lim, T. C. C., Chan, E. H. Y., \& Chong, L. R."The iPad tablet computer for mobile on-call radiology diagnosis? Auditing discrepancy in CT and MRI reporting", Journal. of Digital Imaging, 22012, 5(5), pp. 628-634.

[22] Kaptelinin, V.\&B.A. Nardi, "Activity theory: basic concepts and applications", In CHI '97 Extended Abstracts on Human Factors in Computing Systems, 1997, pp. 158159. Atlanta, Georgia: ACM.

[23] Engeström, Y., "Developmental studies of work as a testbench of activity theory: The case of primary care medical practice", 1993, In S. Chaiklin \& J. Lave (Eds.), "Understanding practice: Perspectives on activity and context”, pp. 64-103, Cambridge, MA: CUP

[24] Hakkinen and Korpela, “A participatory assessment of IS integration needs in maternity clinics using activity theory", International Journal of Medical Information, 2007 Nov-Dec, 76(11-12), pp.843-9.

[25] Karanasios, S. and D. Allen, "Mobile technology in mobile work: contradictions and congruencies in activity systems", European Journal of Information Systems, 2014, 23(5), pp.529-542.

[26] Hashim, N. and M. Jones, "Activity Theory: A framework for qualitative analysis", 4th International Qualitative Research Convention (QRC), 2007, 3-5 September 2007." PJ Hilton, Malaysia.

[27] Barab, S. A., Evans, M. A., \& Baek, E. O., "Activity theory as a lens for characterizing the participatory unit", Handbook of research on educational communications and technology 2, 2004, pp.199-213
[28] Benbasat, I., D.K. Goldstein, M. Mead, "The Case Research Strategy in Studies of Information Systems", MIS Quarterly, 1987. 11(3): p. 369-386.

[29] Yin, RK. "Case study research: Design and methods", Thousand Oaks, CA: Sage, 1994.

[30] Creswell, J.W., "Qualitative inquiry and research design: Choosing among five approaches, 2nd ed. 2007, Thousand Oaks, CA, US: Sage Publications, Inc. xvii, 395.

[31] Morse, J. M., "The Significance of Saturation”, Qualitative Health Research, 1995, 5(2), 147-149

[32] Crabtree, B. F.\&W. L. Miller, "Using codes and code manuals: a template organizing style of interpretation", Doing qualitative research, 1999, 2, pp. 163-177.

[33] Miles, M. B., and A. M. Huberman, "Qualitative data analysis (ed.)", Thousand Oak: CA: Sage., 1994

[34] Braun, V, \& Clarke, V., "Using thematic analysis in psychology", Qualitative research in psychology, 3(2), 2006, pp. 77-101

[35] Ammenwerth, E., A. Buchauer, B. Bludau\&R. Haux, "Mobile information and communication tools in the hospital", International Journal of medical informatics 57(1), 2000, pp.2-40.

[36] Bardram, J. E., \& Bossen, C., "Mobility work: The spatial dimension of collaboration at a hospital". Computer Support Coop Work, 14, 2005, pp.131-160.

[37] Barr, Hammick, Koppel\&Reeves "The effectiveness of interprofessional education: key findings from a new systematic review", Journal of Interprofessional Care, 2010, 24(3), pp.230-41

[38] Reeves, S., Lewin, S., Espin, E., \& Zwarenstein, M., "Interprofessional teamwork in health and social care". Oxford: Wiley Blackwell Publishing Ltd., 2012

[39] Rocci Luppicini and Aceti, "Exploring the Effect of mHealth Technologies on Communication and Information Sharing in a Paediatric Critical Care Unit: A Case Study", International Journal of Health Information System 6 (3), 201, pp.1-19.

[40] Prgomet, M., Georgiou, A., \& Westbrook, J. I., "The Impact of Mobile Handheld Technology on Hospital Physicians' Work Practices and Patient Care: A Systematic Review", JAMIA, 2009, 16(6), pp.792-801.

[41] Kim, D. K., Yoo, S. K., Park, J. J., \& Kim, S. H., "PDA-phone-based instant transmission of radiological images over a CDMA network by combining the PACS screen with a Bluetooth- interfaced local wireless link", Journal of Digital Imaging, 2007, 20(2), pp. 131-139.

[42] Engeström, Y., "Activity theory and individual and social transformation". 1999, In Y. Engeström, R. Miettinen, \& R, "Punamaki, (Eds.), Perspectives on activity theory, pp. 19-38. Cambridge, MA: CUP

[43] Blin, F\&Munro M. “Why hasn't technology disrupted academics' teaching practices? Understanding resistance to change through the lens of activity theory", Computers \&Education, 2008, 50(20), pp.475-490 
Page 3518 